\title{
Prebisch, el Estado y la “DEBILIDAD DEL IMPRESCINDIBLE"
}

\author{
Víctor Ramiro Fernández y Emilia Ormaechea ${ }^{1}$
}

Fecha de recepción: 25 de diciembre de 2017. Fecha de aceptación: 24 de mayo de 2018.

http://dx.doi.org/10.22201/iiec.20078951e.2018.195.62954

RESUMEN. Partiendo de reconocer la centralidad del Estado en la propuesta de Raúl Prebisch, pero señalando, al mismo tiempo, los límites que ésta contenía para problematizar la condición periférica de los Estados latinoamericanos, se analizan los cambios manifestados en relación con el rol del Estado para el desarrollo en la producción temprana del autor en la Comisión Económica para América Latina y el Caribe (Cepal). Con el objeto de explicar aquellos cambios y de reconocer los fundamentos de esa condición periférica, se introducen elementos teórico-analíticos que reconocen las dinámicas conflictuales que históricamente actuaron sobre -y se retroalimentaban en- los Estados latinoamericanos, conformando determinadas estructuras y formas de implicación que les impidieron dirigir una estrategia de industrialización tal como lo planteó el estructuralismo en general, y Prebisch en particular.

Palabras clave: Estados latinoamericanos; Raúl Prebisch; pensamiento económico; centro-periferia, estructuralismo; acumulación capitalista.

Clasificación JEL: B31, E32, 011, O54.

\section{Prebisch, the State, and the "Weakness of the Essential"}

\begin{abstract}
Beginning with the recognition of the centrality of the State in Raúl Prebisch's oeuvre, while at the same time pointing out its limitations when it comes to conceptualizing the peripheral condition of Latin American states, this paper analyzes how the role of the State changed in the author's early body of work at the Economic Commission for Latin America and the Caribbean (ECLAC). Aiming to explain the shift and acknowledge the underpinnings of their peripheral condition, theoretical and analytical elements come to the fore in recognition of the conflicting dynamics that have historically acted on -and fed back into- Latin American states, shaping certain structures and forms of involvement that prevented them from running an industrialization strategy as the broader structuralist school, and Prebisch in particular, would have envisaged it.
\end{abstract}

Key Words: Latin American states; Raúl Prebisch; economic thought; center-periphery; structuralism; capitalist accumulation.

1 Universidad Nacional del Litoral-conicet, Argentina. Correos electrónicos: rfernand@fcjs.unl.edu.ar y eormaechea@fcjs.unl.edu.ar, respectivamente. 
Plantearse la cuestión del Estado puede ser como asomarse a la Torre de Babel. Más aún, si se trata en un marco tan singular y contradictorio como el de América Latina.

(Graciarena, 1984, p. 3)

\section{INTRODUCCIÓN}

Las contribuciones de Raúl Prebisch -y de la Comisión Económica para América Latina y el Caribe (Cepal) - ofrecieron un insumo central (y original) tanto para comprender las dinámicas de las economías capitalistas periféricas, como para orientar las estrategias industrializadoras que, sobre la base de la programación estatal, permitirían superar la condición periférica y dependiente.

Sin embargo, no obstante la centralidad que asumía el Estado en dicha propuesta, lo cierto es que ésta contenía una escasa elaboración de la naturaleza del Estado periférico (Gurrieri, 1987) y del modo en cómo el mismo, a través del impulso a la industrialización, finalmente se involucraba en la reproducción -y no reversión- de aquella condición. Esta cuestión, que no fue problematizada por el autor, fue de todos modos advertida implícitamente, en cuanto se observa que sus referencias al Estado van cambiando a lo largo de su producción teórica.

Ya durante sus primeros años dentro de la Cepal (1949-1963), el Estado pasa de ser concebido - ex ante- como una herramienta estratégica en la planificación del desarrollo, a ser -ex post- un actor cuyo involucramiento opera como generador y no reversor de las dificultades asociadas a la industrialización. Es decir que, en el marco del reconocimiento de la insuficiencia dinámica industrial, el Estado también se transformó en un elemento problemático y en un factor funcional a la reproducción de los límites al desarrollo.

Lo indicado anteriormente abre, al menos, dos interrogantes: ¿Qué factores influyeron en esa variación en la perspectiva de Prebisch?, y ¿por qué el Estado se conformó en un problema para avanzar en las estrategias industrializadoras durante esos ańos?

En el desarrollo del presente trabajo se argumenta que los cambios en las referencias de Prebisch hacia el Estado, desde su apelación como instrumento hasta su percepción como problema, están mediados por una serie de restricciones analíticas que el estructuralismo no pudo resolver completamente y que se asocian a la visualización de la particular y conflictual dinámica sobre 
la que se conformó la naturaleza periférica de esos Estados, y los efectos que ello acarreaba para avanzar en las estrategias de industrialización. La desconsideración de esa dinámica restrictiva se vincula con las dificultades para integrar en su cuerpo teórico:

a) La forma en que los distintos actores, con sus intereses y lógicas, se hacían presentes, tensionadamente, conformando un tipo de configuración estructural e implicativa del Estado que demarcaba su condición periférica.

b) El modo en cómo esa condición periférica terminaba por conformar un actor estructuralmente limitado/r para superar los obstáculos y resolver las tensiones internas, al tiempo que frágil para enfrentar los desafíos crecientes que imponía el capitalismo a escala global.

La consideración de los factores comprendidos en los incisos a) y b) permite llenar un vacío en la producción prebischiana, cuya notable vigencia en la comprensión de la condición periférica del proceso de acumulación demanda ser complementada con una profundización del análisis de la condición periférica de los Estados latinoamericanos, que fue iniciado hacia 1960 al interior y en la periferia intelectual del estructuralismo.

Para avanzar en ese sentido, primero se sintetizaron las referencias cambiantes de Prebisch hacia el Estado durante su ejercicio como Secretario Ejecutivo de la Cepal (1949-1963). Seguidamente, se analizó el proceso histórico de conformación e implicación de los Estados latinoamericanos, desde el cual se propone comprender su devenir como un problema para la estrategia inicialmente propuesta por Prebisch. Para ello, se consideró la forma en cómo éstos fueron insertándose en tres grandes fases globales del capitalismo (Arrighi, 1999), en referencia al periodo de hegemonía británica; su crisis y la emergencia de la hegemonía estadounidense; y la fase de consolidación de esta última en la posguerra, particularmente durante las dos décadas y media en las que tanto esa hegemonía como el estructuralismo se fueron desplegando. El texto se centra en esta última, presentando una doble -pero interdependiente- configuración del Estado, por un lado como relación social, en el que la matriz de actores internos y externos actúa sobre la formas de implicación estatal, condicionando la formación de sus estructuras organizacionales; y, por otro lado, como aparato, donde la calidad de esas estructuras se vuelve habilitante o limitante de determinadas estrategias implicativas tendientes a operar sobre los obstáculos derivados de esa matriz y las formas acumulativas que desarrollan. Finalmente, se presentan las conclusiones del trabajo. 


\section{LOS CAMBIOS EN LAS REFERENCIAS AL ESTADO EN LA PROPUESTA DE PREBISCH}

\section{Del Estado presupuesto...}

En sus primeras publicaciones en la Cepal, Prebisch caracterizó de manera original los problemas de las economías periféricas y ofreció un conjunto de lineamientos para superarlos, sustentados en la industrialización por sustitución de importaciones (ISI). Pero si bien su interés se orientaba a establecer las bases de la planificación para el desarrollo, la centralidad de este concepto no estuvo acompañada por la consideración analítica del Estado, actor encargado de "trazar el programa de desarrollo" (Prebisch, 1952, p. 16). Lo que Prebisch realiza, de manera minuciosa, es un análisis acerca de los criterios para la asignación eficiente de los recursos para incrementar el ritmo de crecimiento, señalando algunas medidas a implementar por los gobiernos respecto las políticas de inversiones y los sectores a estimular.

En este marco, Prebisch asigna un rol central a la intervención del Estado en función de los atributos concernientes a su estatidad, que le permitirían adecuar los comportamientos privados a las expectativas del programa de desarrollo. Principalmente, puede intervenir y/o regular la actividad económica mediante la configuración impositiva, la inversión pública, el control de importaciones y/o la potencial aplicación de gravámenes sobre el gasto y consumo (Prebisch, 1949, 1952).

Ahora bien, la noción de programa de desarrollo no implica la regimentación rigurosa de la economía por parte del Estado, sino que se asocia a "la idea de acrecentar y ordenar juiciosamente las inversiones de capital con el fin de imprimir más fuerza y regularidad al crecimiento" (Cepal, 1953, p. 7). No se trata, entonces, de que el Estado desarrolle una esfera de acción muy dilatada, sino de combinar la iniciativa pública y privada. De allí la importancia que adquieren los recursos estatales para incidir, directa o indirectamente, en el comportamiento de los actores privados.

Por otro lado, la intervención estatal adquiere particular relevancia para la promoción de la IsI. Naturalmente, ésta requiere de medidas de fomento y protección con el fin de estimular la iniciativa privada y ponerla en condiciones de competir con actividades extranjeras de mayor productividad. Entre esas medidas, se incluyen los mecanismos de protección arancelaria, control de cambios y administración de las importaciones.

Como otro aspecto significativo, Prebisch confía en la capacidad del saber experto para el análisis neutral de las necesidades del desarrollo, asociando 
dicho saber con la figura del técnico-economista. No obstante, esta metodología objetiva e imparcial para las cuestiones técnicas-económicas no se manifiesta del mismo modo en cuanto a la toma de decisiones políticas, que admiten diferentes puntos de vista y suelen resolverse mediante soluciones transaccionales (Cepal, 1953; Prebisch, 1952).

Así, el Prebisch que despunta inicialmente su campo teórico focalizado en la identificación del centro y periferia, se propone no sólo contemplar la historia sino actuar sobre ella, apelando en su argumentación a un Estado que asume una tarea gigantesca, y al cual se lo entiende dotado de las propiedades requeridas para actuar en función de los objetivos. Se trata de un Estado sabio, no contaminado por la lógica divergente de las fuerzas sociales, ni tampoco por las ideas en tensión de allí derivadas.

\section{...al Estado descubierto}

Luego de una primera década de intensa presencia del Estado como principal promotor de la industrialización, el humor prebischiano se va a ver alterado progresivamente, pasando de un optimismo posicional hacia un claro descontento. Se denota allí un cambio brusco en el abordaje epistémico, por el cual el lente con el que Prebisch pasa a abordar el Estado no es aquel sustentado en una aproximación conceptual alternativa al dispositivo neoclásico, que emparenta, sin ser subsumido por su originalidad, con el intervencionismo keynesiano. Se trata, en cambio, de un Estado examinado a través del lente del proceso histórico-empírico, a partir del cual aquel teórico se ve obligado a observar el distanciamiento del actor al que le encargara la tarea de industrialización, respecto del que va efectivamente emergiendo del proceso.

Ello se percibe claramente luego de 1955. Pues si bien persistirá el argumento central que le adjudica al Estado "una responsabilidad fundamental para el desarrollo de la economía" (Prebisch, 1956b, p. 1), las reflexiones de este periodo dan lugar a ciertas reconsideraciones sobre su accionar que se alejan de su anterior percepción normativa. Directa o indirectamente, el Estado aparecerá en la producción de estos años (1956-1963) como un actor en gran parte responsable de las numerosas limitaciones que acompañaron el despliegue de la ISI. ${ }^{2}$ 
Su presentación como un problema obedecerá al carácter discrecional de su intervención y apartamiento de los patrones de eficiencia y neutralidad que, supuestamente, debían acompañar su intervención. En realidad, las políticas proteccionistas implementadas fueron generando restricciones muy pronunciadas a la importación, que perjudicaron considerablemente la competencia en el mercado interno (Cepal, 1959b; Prebisch, 1961). También se criticó la creciente participación del Estado en las inversiones de capital, que resultaron ser insuficientes para atender las necesidades inmediatas de la agricultura, el transporte, la energía y la vivienda, dado que el Estado destinaba los recursos disponibles hacia cuestiones improductivas (Prebisch, 1957b). No obstante, para Prebisch, estas distorsiones no eran resultado del intento de industrializar a través de la intervención estatal, sino más bien, de "la improvisación de la política económica o su errónea orientación” (Prebisch, 1957a, p. 5).

El Estado aparece, entonces, como un actor del que ya no puede esperarse que sepa lo que tiene que hacer, sino más bien, como un interventor que se implica inapropiadamente, que actúa ineficientemente en el campo de la política de inversiones de capital e interviene desacertadamente en la economía recreando el persistente problema de la inflación (Prebisch, 1956b, 1957b).

Este viraje en el posicionamiento del Estado no quedó restringido a su forma implicativa, sino que se extendió a la configuración de su estructura organizativa. Lejos de convertirse en un reducto neutral y eficiente para programar, la estructura estatal pasó a ser visualizada como un gran aparato burocrático, contenedor de empleo espurio, cuyo agigantamiento afectaba seriamente el funcionamiento del sistema económico (Prebisch, 1956a, 1963).

Prebisch explica el aumento de los trabajadores estatales debido a la cantidad de actividades desempeñadas por el sector público, pero también por la insuficiencia dinámica de la industria que, al no poder absorber gran parte de la mano de obra disponible, desplazaba los recursos humanos hacia las actividades de servicios y del Estado. Ello implicaba varios problemas, como la presencia de personal incompetente y el desempeño ineficiente de la administración estatal (Prebisch, 1956c); así como el enorme caudal de recursos que se destinaba a solventar el exceso de trabajadores (Cepal, 1959a).

En consecuencia, la intervención del Estado no lograba potenciar las virtudes de la industria como estrategia de desarrollo, en cambio, legitimaba su in-

(Prebisch, 1956a, 1956c) fueron posteriormente generalizados para el análisis de los países latinoamericanos. 
suficiencia dinámica al traccionar sobre los excedentes disponibles sin revertir ni alterar las limitaciones que se iban presentando en el proceso acumulativo. ${ }^{3}$

\section{El Estado descubierto y la persistencia de una ausencia fundamental: la condición periférica de los Estados latinoamericanos}

Esa mutación progresiva que va del Estado presupuesto al análisis de los hechos sufre, no obstante, de una ausencia fundamental: el Estado, en sí mismo, no era observado en su naturaleza y, en ese sentido, en la forma en cómo su condición periférica limitaba estructuralmente su capacidad interventiva. Prebisch omitía, de esta manera, que la naturaleza periférica no era sólo patrimonio de las economías, sino también de los propios Estados. Este aspecto guarda particular relevancia para comprender por qué se manifestó ese cambio en el lente prebischiano, y también para explicar el protagonismo que el Estado asumía en la propuesta industrializadora y los límites que él mismo encontraba históricamente, cuestión que no fue abordada por el estructuralismo.

Ciertamente, mucho sucedió positivamente luego de aquellos años al interior del pensamiento estructuralista que aportó a superar -al menos parcialmente- esa ausencia; particularmente cuando la visión sociológica-política del poder, la dominación y el conflicto perforaron la Cepal e invadieron el análisis estructuralista de la dependencia. ${ }^{4}$ No obstante ello, permanecerá una deuda importante para dar cuenta del papel que las estructuras estatales juegan en la configuración de esa estatidad periférica (Gurrieri, 1987). Es decir, pervivirá una omisión analítica acerca de cómo los procesos socioconflictuales coagulan en determinadas estructuras estatales, condicionando la forma implicativa del Estado y su capacidad para alterar los factores que reproducen la condición periférica.

3 Este posicionamiento más crítico en relación con el Estado encontrará continuidad en los últimos años de producción de Prebisch, hacia fines de los años setenta y principios de los ochenta, cuando el Estado ya es reconocido como un actor que interviene activamente en el marco de las relaciones de poder y de clase, bajo un contexto de avance de las experiencias autoritarias y de ajuste en la región.

4 La consideración de esa matriz y sus vínculos con el Estado (aunque sin teorizar al Estado como objeto de estudio) fue emergiendo en las sucesivas contribuciones del círculo cepalino, particularmente a partir de los trabajos de Graciarena (1984), Medina Echavarría (1963), Cardoso y Faletto (1977). Contextualmente, estas contribuciones se presentaron de manera tensionada con otros enfoques asociados al dependentismo, que discutían la condición y viabilidad del capitalismo en la periferia, y criticaban el rol funcional que asumía el Estado en relación con el modo de producción hegemónico. 
La observación de la forma en cómo aquel examen de las dinámicas sociales, que incorpora el poder y la dominación en las relaciones con el Estado, se complementa con el examen de las estructuras estatales, resultantes históricas de aquellas dinámicas, resulta fundamental para afrontar la limitada comprensión de la naturaleza periférica del Estado y sus restricciones para operar como agente de transformación. Al mismo tiempo, constituye un elemento central para comprender la vulnerabilidad con la que América Latina enfrentó la crisis de la ISI y el proceso de reestructuración emprendido desde entonces.

\section{LA CONDICIÓN PERIFÉRICA DE LOS ESTADOS LATINOAMERICANOS: ESTRUCTURAS ESTATALES Y MECANISMOS DE IMPLICACIÓN}

La configuración organizacional e implicativa de los Estados latinoamericanos constituye un elemento relevante para entender por qué se sostiene la forma periférica de acumulación y se obstaculiza el cambio estructural preconizado por Prebisch (y el estructuralismo en general). Para entender ese posicionamiento central del Estado periférico en la recreación de los obstáculos estructurales que limitan el desarrollo, es importante observar cómo los Estados latinoamericanos fueron conformados y obligados a involucrarse en distintos contextos históricos en los que la relación con el centro iba mutando a partir de los cambios en los procesos de acumulación, el papel de los Estados centrales y los liderazgos hegemónicos.

La configuración estatal latinoamericana tuvo lugar dentro de un contexto de dependencia histórica en el que sus estructuras internas de poder e intereses permanecieron subordinadas a las tendencias que orientan las relaciones con los intereses dominantes en las sociedades metropolitanas (Quijano, 1968). Ante los cambios en el carácter concreto de estas relaciones, corresponden igualmente cambios en las estructuras de poder de nuestras sociedades. Así, va mutando la forma en cómo el Estado periférico organiza sus estructuras $\mathrm{y}$ administra las tensiones-conflictos que tienen lugar tanto al interior de los procesos nacionales, como en el vínculo de esos intereses y actores con aquellos que se propagan con las estrategias impulsadas desde los Estados centrales y las organizaciones supranacionales que controlan.

5 La noción de Estado periférico refiere a una reflexión de orden genérico que procura dilucidar ciertas características que son comunes a los países latinoamericanos, sin dejar de reconocer -en el plano de ese análisis holístico-, la particularidad de los procesos de constitución de los mismos y las especificidades de sus trayectorias históricas. 
Esas mutaciones del Estado periférico tuvieron lugar bajo un conjunto de características particulares, asociadas a un proceso de constitución estatal que se desarrolló en sociedades civiles más frágiles, menos densas y más desiguales que las que tuvieron lugar en Europa. A diferencia del complejo entretejido socio-estatal que fundó las fuentes del poder social (Mann, 2006), América Latina no contó con una conformación estatal desde la sociedad, colocando inversamente al Estado como un temprano generador vertical de mecanismos de poder patrimonialistas y autoritarios para ordenar el conjunto social, sobre la base de una matriz altamente jerárquica, desigual y burocrática (Guimarães, 1997).

Durante el periodo analizado, las estructuras que dieron complejidad a la creciente intervención estatal continuaron esas formas, en un proceso que tendió a la colonización del Estado (O’Donnell, 1993), desactivando su capacidad directiva a medida que aumentaba su protagonismo. Su configuración fragmentaria para atender intereses corporativos disímiles y asimétricos terminó desactivando la posibilidad de contar con una coherencia estratégica intraestatal, fundamental, como lo muestran otras experiencias, para actuar en el redireccionamiento del proceso de acumulación-industrialización (Chibber, 2002; Kholi, 2004) y dar sostenibilidad a las prácticas redistributivas.

Para explicar este proceso, se diferenciaron tres grandes periodos que forman parte de los ciclos del capitalismo y se analizó cómo se fue involucrando el Estado latinoamericano en cada uno de ellos. En última instancia, estos procesos fueron definiendo sus características periféricas e inhabilitaron su conformación como sujeto direccionador del proceso de industrialización. Posteriormente, se centró el análisis en el último de esos periodos, por ser el contexto histórico de producción de la Cepal aquí analizado.

\section{La estatidad periférica en la fase de hegemonía británica}

Desde mediados del siglo xIx y hasta la primera década y media del siglo $\mathrm{xx}$, los países centrales expandieron sus economías sobre un régimen de acumulación extensivo y un modo de regulación competitivo (Aglietta, 1979). Sus Estados centrales administraron el proceso acumulativo, asegurando en lo interno el régimen de propiedad y las condiciones de contractualidad del trabajo. En el plano externo, actuaron como soportes del ciclo de hegemonía británico, protegiendo el proceso de expansión del capital a través del control territorial directo o a través de formas comerciales (como el caso de América Latina) (Granados Erazo, 2010). 
En dicho contexto, los Estados periféricos aparecen estrechamente vinculados a las acciones desarrolladas por los Estados centrales para apuntalar la expansión de su capital, y cumpliendo un papel neurálgico en el ensamble de los vínculos entre ese capital y las oligarquías locales exportadoras (Kaplan, 1969). La estructura estatal resultante combinaba una fuerte centralización (Graciarena, 1984) acompañada de un aparato administrativo de razonable complejidad, para viabilizar la cobertura de derechos y la formación de las infraestructuras que permitían la reproducción de la matriz de intereses, al tiempo que generaba una restringida asimilación en sus estructuras de una sociedad civil organizada frágilmente hasta ese momento (Graciarena, 1984; Kaplan, 1969).

La compleja y subordinada relación que los Estados periféricos desarrollaron con los centrales se basó en un patrón de acumulación socioespacialmente concentrado y orientado hacia afuera, mediante la provisión de los recursos naturales que demandaba el proceso de industrialización del centro, particularmente Gran Bretaña. Así, bajo el comando de las oligarquías nativas dominantes asociadas al capital externo, dicho modelo afirmaba un modo de inserción global supeditado a los requerimientos de las burguesías industrializadoras de los países centrales.

\section{La estatidad periférica bajo la crisis de la hegemonía británica y la emergencia de la hegemonía americana}

Hacia el final de la Primera Guerra Mundial se evidenciaron importantes transformaciones. Desde el punto de vista de los procesos de acumulación, el capitalismo central, esencialmente de la mano de Estados Unidos, introdujo las formas fordistas y tayloristas, estimulando un cambio cualitativo en las formas de valorización, desde formas extensivas hacia formas intensivas (Aglietta, 1979). Estas formas de acumulación intensivas demandaban una nueva forma regulatoria que asegurara la realización de los incrementos de productividad y garantizara la estabilidad socioinstitucional para dar sentido a los procesos de reinversión, necesarios para ampliar la acumulación y legitimación social (Harvey, 1998). Fue en este marco en que, liderando el New Deal, Estados Unidos relevó la posición hegemónica anteriormente desempeñada por Gran Bretaña (Arrighi, 1999).

La forma monopólica (Baran y Sweezy, 1966) que acompañó el régimen de acumulación intensivo se caracterizó por el fuerte impulso a la intervención estatal, a la cual se le demandaba capacidad para administrar nacionalmen- 
te el crédito y crear las condiciones de empleo e inversión que aseguraran la expansión de la tasa de ganancia. Además, la intervención estatal administraría el conflicto social bajo formas de acuerdos neocorporativos que relevaban a las insuficientes formas de representación liberal propias de la hegemonía británica (Maier, 1975).

Dicho contexto, fortalecido por las restricciones creadas por los conflictos bélicos, alentó la búsqueda de mecanismos intranacionales destinados a superar los procesos de sobreacumulación desde el interior de los espacios nacionales (particularmente después de los años treinta). En este marco, las economías nacionales triunfaron sobre el orden monetario internacional erigido bajo la hegemonía británica (Gilpin, 1987).

Los cambios externos empujaron en Latinoamérica una forma bastante generalizada de autarquía obligada que, como en el centro, acicateó un proceso de implicación estatal destinado a crear las condiciones de auto-provisión del crédito y los bienes que antes proveía el mercado externo. Este proceso, conocido como IsI, implicó una alteración complejizadora de la estructura del Estado, desde la que se introdujo un marco regulatorio más activo y se fueron incorporando nuevas funciones y dispositivos institucionales, modificando su composición orgánica y sus vínculos con la economía. Bajo ese nuevo mapa de instituciones y regulaciones, se implementó un complejo de intervenciones que alcanzaban operativamente el abandono del patrón oro, la adopción de políticas de control de cambios y de racionamiento de importaciones, acuerdos bilaterales de comercio y políticas macroeconómicas anticíclicas (Ocampo, 2008).

A través de este proceso de intervención estatal y estímulo a la IsI, América Latina fue alimentando una profunda transformación socioespacial que potenció las tempranas dinámicas de urbanización y proletarización (Hardoy, 1974; Quijano, 1968), así como la ampliación de sectores medios profesionales, densificados por la creación de actividades productivas y de servicios que se le iban conectando directa e indirectamente.

Ello convivía, en distintos modos, con la preservación de la estructura de poder oligárquica, cuya temprana diversificación hacia sectores financieros e inmobiliarios se desarrollaba junto a un comportamiento dominantemente rentista, jerárquico y escasamente innovador (Schneider, 2013), que no contradecía su vocación exportadora, mantenida como principal fuente de divisas.

El nuevo patrón de acumulación se sustentaba en el crecimiento hacia adentro, con la IsI como protagonista central de lo que algunos avizoraban como oportunidad para el despliegue de proyectos nacionales, nutridos con otros actores viabilizadores de un nuevo bloque de poder sobre la base de una 
naciente burguesía industrial y amplios sectores populares (Guillén Romo, 2008). Para ello, se requería de un Estado centralizado y centralizador, dotado de una nueva estructura institucional para viabilizar el proceso. Sin embargo, el Estado enfrentará complejos desafíos internos y externos que lo colocarán problemáticamente en el centro de la escena.

\section{La estatidad periférica durante la consolidación de la hegemonía americana}

Terminada la Segunda Guerra Mundial, en el centro del sistema-mundo, se restableció el poder de las burguesías vernáculas, aunque bajo una nueva coyuntura que reconocía obligadamente a la fuerza de trabajo organizada. Se desplegó un patrón de acumulación monopólico que a las formas intensivas de la productividad fordista le había adosado los acuerdos neocorporativos (Schmitter, 1985). Estos acuerdos, que aseguraban un conjunto de concesiones básicamente redistributivas a favor del trabajo, viabilizaron un esquema de crecimiento sostenido e inigualable entre 1945 e inicios de 1970.

Bajo esta dinámica, el centro consolidaba una posición dominante a partir de una serie de factores de la que el grueso de la periferia carecería. Por una parte, la transitoria concertación de intereses organizados entre capital y fuerza de trabajo no imponía necesariamente un desplazamiento-copamiento del Estado por la sociedad. Aún bajo el condicionamiento de diferentes bloques de poder, éste preservó una capacidad configurativa cuya cualificación resultó neurálgica para viabilizar el acuerdo neocorporativo transitorio e instrumentar su desarrollo. La relevancia que adquirió el Estado en dicha configuración social, y la formación de las estructuras necesarias para ello, se realizó sobre la base de un modo de regulación que tampoco implicaba la supresión de los actores privados por parte del Estado (Goldin, 2012).

Por otro lado, los Estados centrales se involucraron en el proceso de acumulación a partir de interacciones que incluían el soporte del capital local, que lideraba los procesos de industrialización, a los que procuraban apuntalar y sostener en su dinámica expansiva externa. Una parte sustantiva de la fuerza de trabajo se integraba a los circuitos abiertos por ese capital endógeno y sus procesos dinámicos de expansión. El Estado, por su parte, se implicaba en un proceso siempre inestable y conflictual con la potenciación de un capital monopólico de base local-nacional que procuraba controlar los procesos productivos tecnológicos más avanzados y, desde allí, expandirse a nivel nacional e internacional. La empresa transnacional fue naciendo bajo este periodo como 
un agresivo actor de penetración global, apuntalado por sus Estados y en una acción retroalimentaria con éstos (Cardoso y Faletto, 1977; Gilpin, 1987).

Ahora bien, ninguno de esos atributos estará presente en la periferia latinoamericana, y en ello intervienen factores que actuarán sobre la rápida creación de restricciones en su economía política y en las posibilidades de edificar un Estado dotado de capacidad para habilitar aquella demanda de transformación estructural promovida por Prebisch.

Para dar cuenta de ello, y no obstante las especificidades nacionales e intranacionales, es necesario considerar la forma en cómo se estructuraron los actores sociales y sus intereses, y el modo en cómo sus prácticas influyeron en la configuración de la estructura y el tipo de implicación estatal. Desde allí, gana factibilidad la explicación acerca de cómo estos últimos elementos actuaron en las limitaciones para superar los obstáculos emergentes a nivel del proceso de acumulación.

\section{Actores e intereses: de preservados, consolidados, activados y ausentes}

A diferencia del proceso que tomó lugar en el este asiático, el proceso de industrialización latinoamericana no corrió paralelo a una reforma estructural en el régimen de tenencia de la tierra; por tanto, no alteró la estructura de poder de las oligarquías nativas (Kay, 2002). La pervivencia del poder de estos grupos, así como el liderazgo asociado al capital externo para hegemonizar el bloque que orientaba el proceso de acumulación (Romero y Rofman, 1974), convivió con la activación de una amplia panoplia de actores a nivel local, representantes del pequeño capital productivo y comercial, y del ampliado mundo del trabajo, resultado del proceso de IsI y urbanización de entreguerras (Graciarena, 1990).

Bajo este complejo cuadro actoral, las crecientes demandas de esos activados (O’Donnell, 1972) pasó a ser atendida por el Estado mediante la ampliación del régimen político, en el que no estuvieron ausentes diversas formas de clientelismo (Graciarena, 1984) y corporativización (Kaplan, 2015). Ello convivía con otros dos procesos asociados: uno, a la incapacidad de resolver la continuidad del proceso de acumulación a través de la isı y superar sus cuellos de botella; y otro, a la incapacidad del Estado para enfrentar esas limitaciones y destrabar las tensiones derivadas de ello.

La matriz social con la que interactuó el Estado quedó progresivamente dominada por las tensiones producto de los requerimientos no convergentes entre los actores que formaban el bloque de poder, integrado por las oligar- 
quías locales y el capital externo (Peña, 1979; Romero y Rofman, 1974), y la atención de los activados y crecientemente agremiados actores subalternos, que pugnaban por una distribución sostenida del ingreso. Esa tensión, a su vez, tenía lugar bajo la ausencia de una burguesía industrial local, dotada de capacidad de aprendizaje intensivo y propensión a desarrollar las formas no rentistas necesarias para el éxito de la IsI (Hirschman, 1968), algo que en los casos de capitalismo tardío estuvo claramente presente (Gerschenkron, 1962).

La ausencia de este actor en medio de ese proceso de tensiones fue posicionando al Estado como epicentro de soluciones transitorias que lo hacían incapaz de operar como un resolutor de los problemas estructurales. Para comprender lo anterior, es necesario analizar al Estado desde dos dimensiones: 1) como parte de una relación social (Jessop, 2010; Poulantzas, 1978), y 2) como aparato institucional específico. Al tiempo que, en tanto relación social, la matriz de actores, sus estrategias e intereses conforman el aparato estatal, las especificidades de éste resultan un elemento esencial para entender las (in) capacidades del Estado periférico latinoamericano para resolver los límites en el proceso acumulativo generados desde dicha matriz y comportamientos.

\section{El Estado latinoamericano como relación social: actores, intereses y comportamientos configurativos}

El Estado, en tanto resultado-integrante de una relación social, expresa en su constitución y funcionamiento una vinculación condicionada por aquella matriz de actores sociales. No sólo condensa determinadas relaciones de fuerza (Poulantzas, 1978) e impone a partir de ello una forma de dominación vinculada a las relaciones de clase, sino que responde a determinadas lógicas de acción en función del poder de los actores de esa matriz social y de lo que dichos actores demandan desde su posicionamiento y estrategias.

La preservación del poder concentrado al interior del bloque dominante que direccionaba el proceso de acumulación actuó fortaleciendo su poder de acción sobre el Estado, limitando su capacidad para desarrollar una implicación que efectivamente redefina los comportamientos de los actores capitalistas dominantes hacia un proceso acumulativo más complejo. De avanzar en ello, esencialmente a través del direccionamiento de las inversiones privadas hacia formas vinculadas con la producción de bienes de capital, se hubiera comprometido la posición de poder y la lógica acumulativa, concentrada y rentista, sobre la cual mantenían el control del proceso de acumulación. Esta incapacidad se convirtió en un factor decisivo para disociar el proceso de 
IsI de un proyecto de desarrollo integral, hábil para transformar las formas de subalternidad externas y las condiciones de inclusión socio-productivoespacial internas, como lo había impulsado Prebisch y pretendido continuar la Cepal.

Las limitaciones para operar sobre el proceso de acumulación, producto de esa matriz social y las formas de implicación que demandaron al Estado, conllevaban una restricción intrínseca para superar la etapa fácil de la ISI. A medida que dicha fase se agotaba, y no obstante la importancia que la actividad industrial adquiría en la mayoría de los aparatos económicos, se potenciaban los efectos de la vulnerabilidad externa (Ffrench-Davis et al., 1998) al tiempo que, internamente, se mantenían y profundizaban las heterogeneidades estructurales (Pinto, 1976).

La apelación al capital externo fue ganando peso entre los argumentos que exploraban las posibles salidas para América Latina. Sin embargo, las empresas transnacionales que arribaron a la región tendieron a desarrollar una lógica de enclaves, importando paquetes tecnológicos en un mercado hiperprotegido y procesos productivos con alta integración vertical, donde escaseaban los encadenamientos productivos intranacionales, potenciando, finalmente, la transnacionalización del proceso de acumulación (Sunkel, 1971). En consecuencia, la estructura resultante promovió un patrón de decisiones exógeno, desigualador y poco dinámico.

Mientras ello tenía lugar en el patrón de desarrollo, el proceso de legitimación del Estado para conducir las tensiones entre el bloque de poder y el grueso cuerpo social-espacial activado por la ISI se iba desmoronando. Los reclamos distributivos chocaban en su sostenibilidad con el mantenimiento de una estructura productiva sustentada en los intereses del bloque de poder dominante. La resolución de esas tensiones, muchas presentadas bajo situaciones de empate hegemónico (Portantiero, 1977), fue obligando finalmente a emprender una nueva y doble implicación estatal. Por un lado, a través de formas autoritarias que desactivaban temporalmente a los actores activados bajo la IsI (O’Donnell, 1972). Y, por otro lado, desplegando procesos que combinaban la reducción de subsidios y beneficios, así como estrategias devaluatorias (Dornbusch y Edwards, 1991) que degradaban el salario y fortalecían el posicionamiento de los actores dominantes del capital, dejando inalterada la estructura de poder sobre la que se configuraban las formas de reproducción interna (heterogénea y desigualadora) e inserción internacional (primarizada).

El proceso no resultaba perenne, sino que duraba hasta que los desactivados se activaban nuevamente, reclamando al Estado una atención que recreaba 
el escenario de tensiones, principalmente a partir de acciones legitimatorias que colocaban la dimensión distributiva en el centro de la construcción y acción estatal.

\section{El Estado como aparato: la construcción de los laberintos de la incapacidad}

El proceso analizado se fue profundizando durante la posguerra y adquirió su forma crítica hacia finales de los años sesenta del siglo xx, dando lugar a dos interrogantes que afectan la otra dimensión que comprende la estatidad: la de sus estructuras. ¿Cómo esa dinámica que entrelazó la matriz social dominante y potenciaba las tensiones-conflictos con el complejo de actores subalternosactivados se cristalizó en las estructuras del Estado periférico latinoamericano? ¿Cómo, a su vez, las características de esas estructuras afectaban -y se retroalimentaban con- los requerimientos que surgían del agotamiento del isi y las formas distributivas?

El Estado configurado fue un Estado capturado, direccionado por y no direccionante de los actores dominantes de la matriz social. Respondiendo a las demandas de los actores más organizados, fue conformando múltiples organizaciones que densificaban su presencia, pero diluían progresivamente la posibilidad de lograr una coordinación estratégica para direccionar a los actores que conducían el patrón acumulativo. El resultado fue un Estado crecientemente omnipresente pero al mismo tiempo estructuralmente débil en términos de $\mathrm{Migdal}^{6}$ (2011).

Recreando una tradición patrimonialista, concentrada y excluyente de la sociedad civil, el Estado procuró profundizar bajo esta fase de posguerra un proceso de inclusión sociopolítico y económico apelando a una lógica de asistencia vertical y muchas veces autoritaria, con la que pretendía responder a las múltiples demandas corporativas que emanaban de la sociedad. Aunque mantenía la desigualdad y las jerarquías, activaba y organizaba simultáneamente a una amplia panoplia de nuevos actores, representantes de la fuerza de trabajo y de segmentos medios (Guimarães, 1997), creando una multiplicidad

6 De acuerdo con Migdal (2011), en los países del tercer mundo, la existencia de numerosas organizaciones sociales con posibilidad de ejercer un control social efectivo tiene un resultado decisivo sobre la posibilidad de que los Estados expandan mucho sus capacidades. La fuerza de estas organizaciones fragmentadas influye en las prioridades de los dirigentes del Estado y en la posibilidad de implementar-imponer leyes y políticas. En última instancia, los dirigentes del Estado pueden debilitar intencionalmente las propias estructuras estatales encargadas de imponer las reglas, y el Estado puede fortalecer deliberadamente a quienes aplican reglas que van en contra de las suyas propias. 
de instancias de cobertura para atender dichas demandas, y abonando progresivamente a un proceso de "feudalización del Estado por las corporaciones" (Portantiero, 1989, p. 92).

En tanto, a medida que se agotaban los recursos para las intervenciones distributivas asociadas a la lógica del populismo y la etapa fácil de ISI, se amplió al interior del Estado la formación de una tecnoburocracia con inspiración modernizadora (Guimarães, 1997), que intentaba imponerse cupularmente, fijando interpretaciones y prácticas que empalmaban con aquellas de las fracciones del capital que hegemonizaban el bloque de poder (O'Donnell, 1972). Fue, justamente, durante la segunda mitad de los años sesenta en que tuvo lugar el desarrollo de los anillos burocráticos (Cardoso, 1975), en referencia a las relaciones entre el Estado y los grupos de interés mediante las cuales el primero atendía clientelarmente los requerimientos patrimonialistas de los grupos más concentrados, por medio de sus managers y diversos conductos organizacionales (Castellani, 2002). Así, profundizaban la captura de rentas, alentaban el desmantelamiento de su papel distribucionista y depositaban en el capital externo la esperanza -nunca materializada- de la modernización del desarrollo.

El decurso de la realidad fue mostrando una trayectoria estatal en la que, paradojalmente, a medida que se potenciaba la necesidad de contar con un Estado gerschenkroniano, que debía afrontar aún mayores desafíos que en el centro, se diluía la posibilidad de conformar en los mismos una estructura idónea y bien articulada para conducir el cambio de comportamientos de los actores dominantes.

La imposibilidad de dotar al Estado de una estructura organizacional y operativamente coherente afectó la capacidad de actuar sobre el proceso acumulativo, por la imposibilidad de orientar el comportamiento de los capitalistas locales y externos hacia un patrón de acumulación endógeno y dinámico. Las estructuras desarrolladas atentaban contra la demanda de un Estado con capacidad para direccionar a las fracciones del capital hacia la formación de un núcleo productivo industrial en el que los actores locales fueran capaces de alcanzar actividades de mayor complejidad tecnológica, revirtiendo la lógica cortoplacista y extranjerizante hacia programas de largo plazo, que posicionaran progresivamente a los actores vernáculos en el demandante segmento de los bienes de capital.

La estructura resultante cristalizaba las tensiones-contradicciones de una compleja matriz sociopolítica (Cavarozzi, 1996), en la que intereses privados y públicos se interpenetraban por múltiples mecanismos, reflejando, por un lado, la inexistencia de un propósito en las elites -dominantes y subalternas-, 
internas y externas al aparato político, de habilitar la formación de un Estado direccionador; y, por otro, la voluntad de la dirección institucional y política de los subalternos de capturar rentas más allá del funcionamiento efectivo del patrón acumulativo.

Al tiempo que el propio Estado se convertía en el más neurálgico de los actores para resolver la tensiones y legitimar el escenario conflictual, la ampliación de su estructura fragmentaria y colonizada, resultante de todo ello, alejaba crecientemente la posibilidad de que, ahora desde el Estado hacia la sociedad, tuviera lugar una implicación alternativa y direccionante, capaz de superar aquella tensión entre los actores dominantes, que refrenaban el cambio acumulativo, y aquellos activados que demandaban la profundización de las acciones distributivas. Su acrecentada presencia alentaba, en cambio, una práctica cortoplacista, sustentada en capitalizar los beneficios selectivos obtenidos a través de la capacidad de colonización y multiplicación de diferentes agencias estatales (O’Donnell, 1993). Mediante esa modalidad, y a medida que acrecentaba su protagonismo, el Estado devenía un actor principal que resultaba incapaz de tejer un guion que obligue al resto del elenco a actuar en favor de los requerimientos de un proceso de acumulación estructuralmente más autónomo y más dinámico. Expresado casi como un oxímoron, el Estado latinoamericano se volvió una expresión de la debilidad creciente del crecientemente imprescindible.

En última instancia, la imposibilidad de resolver a nivel del proceso de acumulación las tensiones e inconsistencias de los intereses divergentes entre dinámicas distributivas cupulares con la preservación de una estructura de poder basadas en un capitalismo extrovertido y rentista, terminó forzando una internalización caótica de esas tensiones en el Estado, dando lugar a una reproducción estatal con rasgos "espurios y morbosos", para usar las propias expresiones de Prebisch (1963, p. XVIII).

Ello no sólo contribuyó a darle un sello de especificidad -negativa- a su condición periférica, sino que finalizó diluyéndole como herramienta estratégica para alterar ese patrón acumulativo y revertir aquella condición. Ante tal fragmentaria y descoordinada reproducción de su infraestructura organizacional, el Estado nunca logró conformar un núcleo implicativo organizacionalmente coherente y técnicamente capacitado desde el cual controlar y direccionar recursos estratégicos -como el fiscal y financiero-; aspectos en los que se fue distanciando de las ascendentes experiencias del este asiático (Fernández, 2017).

La trayectoria del Estado latinoamericano fue conformando así una fiel expresión de la debilidad del imprescindible, desde cuya configuración orga- 
nizacional y operativa forjó su incapacidad para: 1) alterar los obstáculos del proceso de industrialización, por no contar con la habilidad para disciplinar y condicionar estratégicamente al capital interno y externo; 2) resolver las tensiones intranacionales entre ese capital que hegemoniza el bloque de poder y la activación distributiva de los sectores subalternos; 3) y evitar el oximorónico debilitamiento que acompañó su creciente intervención estatal.

\section{CONCLUSIONES}

Partiendo de reconocer que el estructuralismo latinoamericano, particularmente la producción teórica de Prebisch, no contiene una reflexión acerca de la naturaleza del Estado periférico, se propuso situar centralmente la especificidad del Estado latinoamericano en el marco de su propuesta de desarrollo a fin de comprender no sólo los cambios de humor de Prebisch respecto su rol en dicho proceso, sino también para dar cuenta de ciertas restricciones analíticas para identificar las formas mediante las cuales el Estado -implicado activamente en la promoción de la ISI-, finalmente se convirtió también en un problema para avanzar en los objetivos pregonados por el autor.

De esa manera, aunque Prebisch no problematizó el rol del Estado, sí fue advirtiendo sobre las dificultades asociadas al tipo de intervención que fue desplegando en el proceso histórico, que se alejaban de la concepción de neutralidad y eficiencia predominante en sus escritos iniciales en la Cepal. El análisis ex post le permitió advertir que las prácticas de involucramiento posicionaban al Estado más bien como un generador, legitimador y no-reversor de los problemas asociados a las limitaciones que manifestaba la ISI para superar la condición periférica-dependiente de la región. Sin embargo, aquel análisis resultaba deficitario, pues carecía de una precisión de aquellos aspectos relacionados con las formas constitutivas e implicativas que dan especificidad a la condición periférica del Estado, y la consideración de la forma en cómo ello operó retroalimentariamente en/con la reproducción de la condición periférica que tenía lugar a nivel del proceso acumulativo.

Al precisar las calidades periféricas del Estado latinoamericano bajo la lógica formada por el complejo proceso de elementos internos y externos analizados, es posible vislumbrar el conjunto de condicionamientos bajo los que tuvo lugar dicho cambio evaluatorio de Prebisch sobre el Estado, así como el papel central del Estado en la imposibilidad de superar los limitantes emergentes del proceso de IsI. Dicho análisis contribuye a identificar, entonces, no sólo los aspectos estructurales que condicionaron la capacidad interventiva 
del Estado, sino también a comprender la imposibilidad de configurar una estatidad dotada de ciertas cualidades en sus estructuras que le permitan direccionar el proceso de transformación de las dinámicas de acumulación, tal como lo pregonaba Prebisch, y tal como ocurrió en otros espacios geográficos de la periferia. En cambio, los crecientes mecanismos de configuración e implicación, fragmentados y cooptados, se orientaron a atender y legitimar la conflictividad persistente en la región producto de la tensión entre los mayores reclamos de los actores activados y la imposibilidad de habilitar un patrón de acumulación industrial que dé sostenibilidad a las crecientes demandas de redistribución.

Como consecuencia de ese proceso, el Estado no sólo fue incapaz de dirigir la transformación de la estructura productiva latinoamericana bajo el impulso a la ISI, sino que configuró su creciente debilidad para actuar y resolver los desafíos que emergieron en la región cuando, años más tarde, comenzó un proceso de reestructuración global liderado por el Consenso de Washington. Finalmente, cuando el Estado fue puesto en el banquillo de los acusados como el principal imputado de los problemas que marcaban el retroceso de la región (Pinto, 1987), las condiciones emergentes de la debilidad del imprescindible hicieron que las respuestas desarrolladas por la región ante los procesos de globalización no fueran por aquellos caminos impulsados por el estructuralismo en general y el último Prebisch en particular.

\section{BIBLIOGRAFÍA}

Aglietta, M. (1979), A Theory of Capitalist Regulation, London, New Left Books.

Arrighi, G. (1999), El largo siglo XX, Madrid, Akal.

Baran, P. y Sweezy, P. (1966), Monopoly Capital. An Essay on The American Economic and Social Order, New York, Modern Reader.

Cardoso, F. H. (1975), "La cuestión del Estado en Brasil", Revista Mexicana de Sociología, vol. 37, núm. 3.

Cardoso, F. H. y Faletto, E. (1977), Post scriptum a "Dependencia y Desarrollo en América Latina”, Desarrollo Económico, vol. 17, núm. 66.

Castellani, A. G. (2002), "La gestión estatal durante los regímenes políticos burocrático- autoritarios. El caso argentino entre 1967 y 1969”, Sociohistórica, núm. 11-12.

Cavarozzi, M. (1996), El capitalismo político tardío y su crisis en América Latina, Chile, Ediciones Homo Sapiens. 
Cepal (1953), Estudio preliminar sobre la técnica de programación del desarrollo económico, Río de Janeiro, Naciones Unidas.

(1959a), Análisis y proyecciones del desarrollo económico. El desarrollo económico de la Argentina, México, Naciones Unidas.

(1959b), El mercado común latinoamericano y el régimen de pagos multilaterales, México, Naciones Unidas.

Chibber, V. (2002), "Bureaucratic Rationality and the Developmental State", AJS, vol. 107, núm. 4.

Dornbusch, R. y Edwards, S. (1991), The Macroeconomics of Populism, University of Chicago Press.

Fernández, V. R. (2017), La trilogía del erizo-zorro. Redes globales, trayectorias nacionales y dinámicas regionales desde la periferia, Barcelona, AnthroposSiglo XXI Editores-Ediciones UNL.

Ffrench-Davis, R., Muñoz, O. y Palma, J. G. (1998), "The Latin American Economies (1950-1990)", en L. Bethell (ed.), Latin America. Economy and Society since 1930, Cambridge, Cambridge University Press.

Gerschenkron, A. (1962), Economic Backwardness in Historical Perspective, Cambridge, Harvard University Press.

Gilpin, R. (1987), The Political Economy of International Relations, New Jersey, Princeton University Press.

Goldin, A. (2012), "Corporativismo, neocorporativismo y libertad sindical", Derecho Laboral: Revista de Doctrina, Jurisprudencia e Informaciones Sociales, núm. 247.

Graciarena, J. (1984), "El Estado latinoamericano en perspectiva. Figuras, crisis, prospectivas", Pensamiento Iberoamericano, vol. 5.

(1990), "Estado periférico y economía capitalista: transiciones y crisis", en P. González Casanova (ed.), El Estado en América Latina. Teoría y práctica, Siglo XXI Editores-Universidad de las Naciones Unidas.

Granados Erazo, O. (2010), "De la hegemonía británica a la hegemonía estadounidense. Una transición económica en Argentina y Brasil, 1870-1930", Revista de Relaciones Internacionales, Estrategia y Seguridad, vol. 5, núm. 2. Guillén Romo, A. (2008), "Modelos de desarrollo y estrategias alternativas en América Latina”, en E. Correa, J. Deniz y A. Palazuelos (eds.), América Latina y desarrollo económico, Madrid, Akal.

Guimarães, R. (1997), El Leviatán acorralado: continuidad y cambio en el papel del Estado en América Latina. Serie Ensayos, Santiago, Instituto Latinoamericano de Planificación Social y Económica.

Gurrieri, A. (1987), "Vigencia del Estado planificador en la crisis actual", Revista de la Cepal, núm. 31. 
Hardoy, J. (1974), "El proceso de urbanización en América Latina”, Monografías, núm. 2.

Harvey, D. (1998), La condición de la posmodernidad. Investigación sobre los orígenes del cambio cultural, Amorrortu Editores.

Hirschman, A. (1968), "La economía política de la industrialización a través de la sustitución de importaciones en América Latina”, Trimestre Económico, vol. 35, núm. 104.

Jessop, B. (2010), "The State and Power", en S. R. Clegg y M. Haugaard (eds.), The SAGE Handbook of Power 2009, London, SAGE Publications.

Kaplan, M. (1969), Formación del Estado nacional en América Latina, Buenos Aires, Amorrortu Editores.

(2015), "La crisis del Estado nacional latinoamericano", Estudios Interdisciplinarios de América Latina y el Caribe, vol. 1, núm. 2.

Kay, C. (2002), "Reforma agraria, industrialización y desarrollo ¿Por qué Asia Oriental superó a América Latina?", Debate Agrario, núm. 34.

Kholi, A. (2004), State Directed-Development: Political Power and Industrialization in the Global Periphery, Cambridge, Cambridge University Press.

Maier, C. (1975), Recasting Bourgeois Europe. Stabilization in France, Germany and ltaly in the Decade after World War I, Princeton University Press.

Mann, M. (2006), "El poder autónomo del Estado: sus orígenes, mecanismos y resultados", Revista Académica de Relaciones Internacionales, núm. 5.

Medina Echavarría, J. (1963), Consideraciones sociológicas sobre el desarrollo económico de América Latina, Mar del Plata, Naciones Unidas.

Migdal, J. (2011), Estados débiles, Estados fuertes, México, Fondo de Cultura Económica.

O’Donnell, G. (1993), “Acerca del Estado, la democratización y algunos problemas conceptuales. Una perspectiva latinoamericana con referencias a países poscomunistas”, Desarrollo Económico, vol. XXXIII, núm. 130.

(1972), Modernización y autoritarismo, Buenos Aires, Paidós.

Ocampo, J. (2008), "Hirschman, la industrialización y la teoría del desarrollo", Desarrollo y Sociedad, primer semestre.

Peña, M. (1979), Antes de mayo. Formas sociales del trasplante español al nuevo mundo, Buenos Aires, Ediciones Fichas.

Pinto, A. (1976), "Notas sobre los estilos de desarrollo en América Latina", Revista de la Cepal, primer semestre.

(1987), "La ofensiva contra el Estado-económico", Estudios CIEPLAN, núm. 21.

Portantiero, J. C. (1977), "Economía y política en la crisis argentina: 19581973”, Revista Mexicana de Sociología, vol. 39, núm. 2. 
(1989), "La múltiple transformación del Estado latinoamericano", Nueva Sociedad, núm. 104.

Poulantzas, N. (1978), State, Power, Socialism, London, New Left.

Prebisch, R. (1949), "El desarrollo económico de la América Latina y algunos de sus principales problemas", Desarrollo Económico, vol. 26, núm. 103.

(1952), Problemas teóricos y prácticos del crecimiento económico, Santiago, Naciones Unidas.

(1956a), "Informe preliminar acerca de la situación económica de Argentina”, Trimestre Económico, vol. 23, núm. 89.

(1956b), La iniciativa privada, la industria y la programación del desarrollo económico, Cepal.

(1956c), "Planes de recuperación económica de la Argentina", Trimestre Económico, vol. 23, núm. 86.

(1957a), Exposición del señor Raúl Prebisch, en la primera sesión plenaria del séptimo periodo de sesiones, Bolivia, Naciones Unidas.

(1957b), "La política económica de los países menos desarrollados", Revista Colombiana. Revista de la Contraloría General de la República, vol. 12, núm. 35.

(1961), La respuesta de la América Latina a una nueva política de cooperación internacional, Santiago de Chile, Cepal.

(1963), Hacia una dinámica del desarrollo latinoamericano, Cepal.

Quijano, A. (1968), "Dependencia, cambio social y urbanización en Latinoamérica", Revista Mexicana de Sociología, vol. XXX, núm. 3.

Romero, L. A. y Rofman, A. (1974), Sistema socioeconómico y estructura regional en la Argentina, Buenos Aires, Amorrortu Editores.

Schmitter, P. (1985), "Neocorporativismo y Estado", REIS, núm. 31.

Schneider, B. R. (2013), Hierarchical Capitalism in Latin America: Business, Labor, and the Challenges of Equitable Development, Cambridge, Cambridge University Press.

Sunkel, O. (1971), "Capitalismo transnacional y desintegración nacional en América Latina”, Estudios Internacionales, vol. 4, núm. 16. 
